Historic, archived document

Do not assume content reflects current scientific knowledge, policies, or practices. 
$F>644$

FUUH BURINING RATES OF

DOWNWARD VERSUS

HORIZONTALIY

SPREADING FIRES

William H. Frandsen

Robert D. Schuette

\section{n}

(n)

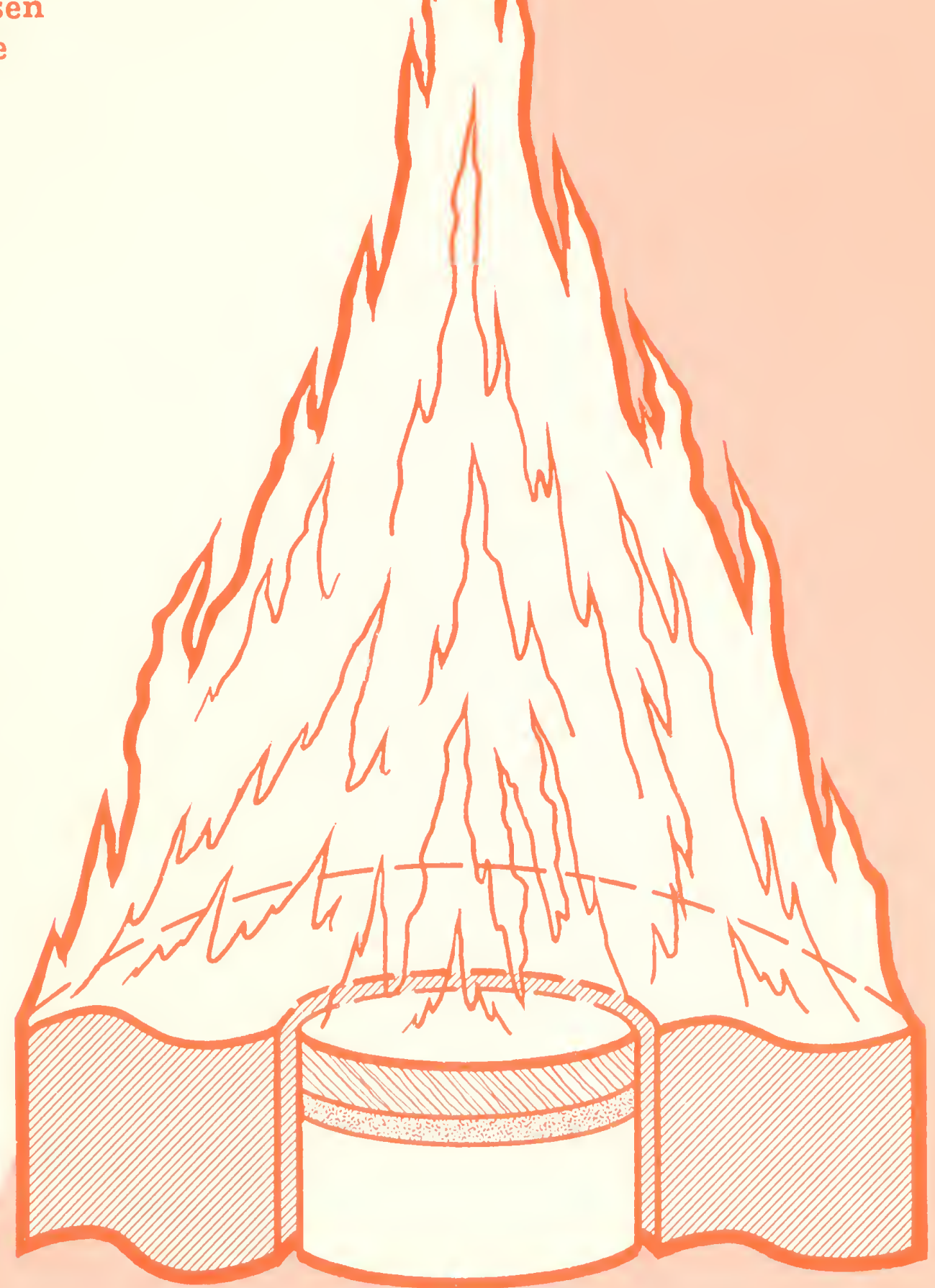

USDA Forest Service Research Paper INT-214

INTERMOUNTAIN FOREST AND RANGE EXPERIMENT STATION

FOREST SERVICE, U.S. DEPARTMIENT OF AGRICULTURE 


\title{
FUEL BURNING RATES OF DOWNWARD VERSUS HORIZONTALLY SPREADING FIRES
}

\author{
William H. Frandsen \\ and \\ Robert D. Schuette
}

INTERMOUNTAIN FOREST AND RANGE EXPERIMENT STATION

Forest Service

U.S. Department of Agriculture

Ogden, Utah 84401 


\section{THE AUTHORS}

WILLIAM H. FRANDSEN is a Research Physicist stationed at the Northern Forest Fire Laboratory in Missoula, Montana. He received his B. A. in physics and mathematics from Lewis and Clark College in 1954, and his M.A. in physics from the University of Oregon in 1960. Frandsen was employed from 1955-1967 as a physicist at the Naval Weapons Center at China Lake, California. While there he was involved in two fields of study: infrared detection systems and the effects of ultrasound on metals. Since 1967, Frandsen has been with the Fire Fundamentals research work unit at the Northern Forest Fire Laboratory, where he is responsible for the technical planning and execution of research concerned with the thermodynamics of the fire and its interaction with the fuel complex.

ROBERT D. SCHUETTE joined the Fire Physics project at the Northern Forest Fire Laboratory in 1962. He transferred into the Fuel Science research work unit in 1970 and worked as a Physical Science Technician. He received his B.A. degree in physical sciences from the University of Montana in 1962. 


\section{CONTENTS}

Page

INTRODUCTION . . . . . . . . . . . . . . . 1

EXPERIMENTAL PROCEDURE . . . . . . . . . . . 3

RESULTS . . . . . . . . . . . . . . . . . . 3

DISCUSSION . . . . . . . . . . . . . 6

PUBLICATIONS CITED . . . . . . . . . . . . 8

APPENDIX .................. . . 9

Appendix A--Terms . . . . . . . . . . . . 10

Appendix B--Derivation of Maximum Load-Loss Rate . . 11

Appendix C--Statistical Test . . . . . . . . 12 


\section{RESEARCH SUMMARY}

Maximum load-loss rate within the combustion zone of a vertically (downward) spreading fire was obtained for excelsior $(0.07 \mathrm{~cm}$ in crosssection) at bulk densities from 0.0016 to $0.026 \mathrm{~g} / \mathrm{cm}^{3}$. Fuel was contained within a continuously weighed circular wire mesh basket $1 \mathrm{ft}^{2}\left(929 \mathrm{~cm}^{2}\right)$ in circular area and $0.5 \mathrm{ft}(15.2 \mathrm{~cm})$ deep, surrounded by a separate annular basket of fuel, to minimize edge effects. Load-loss rates were similar to those obtained by Rothermel (1972) for horizontally spreading fires in the same fuel at the same bulk densities.

The peak rate of load loss per unit area exhibits a strong dependence upon bulk density for both vertically and horizontally spreading fires. The maximum of this peak rate occurs at the same bulk density in the two cases. Because of these similarities, this method offers an alternative for investigating the combustion dynamics of fire; moreover, the vertical array is much easier to use than the horizontal array. 


\section{INTRODUCTION}

Frandsen and Rothermel (1972) have presented a method of measuring the energyrelease rate of a spreading fire through the load-loss rate of a section of the fuel bed. This paper describes an alternative fuel bed that uses less fuel, that takes less time to construct, and that is less complex to measure than the fuel bed used previously. Fuel arrays to be examined are contained within a circular basket. The top is ignited uniformly over the surface and the basket's fuel load loss is continuously recorded as the fire moves vertically downward.

Rothermel (1972) has shown that the fundamental dynamics of fire spreading through a porous fuel array can be expressed through $\Gamma$, the reaction velocity, the ratio of the efficiency of mass degradation during pyrolysis to the elapsed time of pyrolysis experienced during fire spread. Its product with $w_{n}$, the net original ovendry load of a fuel bed, is equivalent to $\dot{w}$, the maximum load-loss ${ }^{n}$ rate of a portion of the fuel bed as the fire spreads through the fuel:

$$
\dot{w}=w_{n} \Gamma
$$

The method of obtaining $\dot{w}$ experimentally has been covered by Frandsen and Rothermel (1972) in their investigation of the reaction intensity of the combustion zone of a spreading fire. (The rate $\dot{w}$ is properly a loss; however, the negative sense is internally compensated.) The reaction intensity, $I_{R}$, is another important dynamic parameter of the fire. $1 \mathrm{t}$ is the total energy-release rate evolved from the combustion zone, and is related to $w$ through $h$, the low heat of combustion:

$$
1_{\mathrm{R}}=h \dot{w}=h w_{n} \Gamma
$$

The load-loss rate, $\dot{w}$, is an important basic parameter that relates to the dynamics of a spreading fire. The maximum load-loss rate of a burning fuel array can be obtained by monitoring the load of a basket of fuel as the fire moves with a horizontal plane downward through the basket (fig. 1). The purpose of this paper is to show that, for excelsior, the fuel basket experiences a maximum load-loss rate similar to that experienced by a horizontal fuel bed slice $\Delta x$, (fig. 2) at the same packing ratio, the ratio of the bulk density to the particle density. Although the bed fire travels horizontally, the observer at $\Delta x$ views a downward moving front that is similar to the front illustrated in figure 1; namely, as $\Delta x$ tends to zero, the boundaries of the pyrolysis zone can be easily approximated as horizontal planes. Because only the fuel slice is weighed, the rate of change of the load within the slice is hypothesized to be identical to the rate of change of the load in the burning basket. 


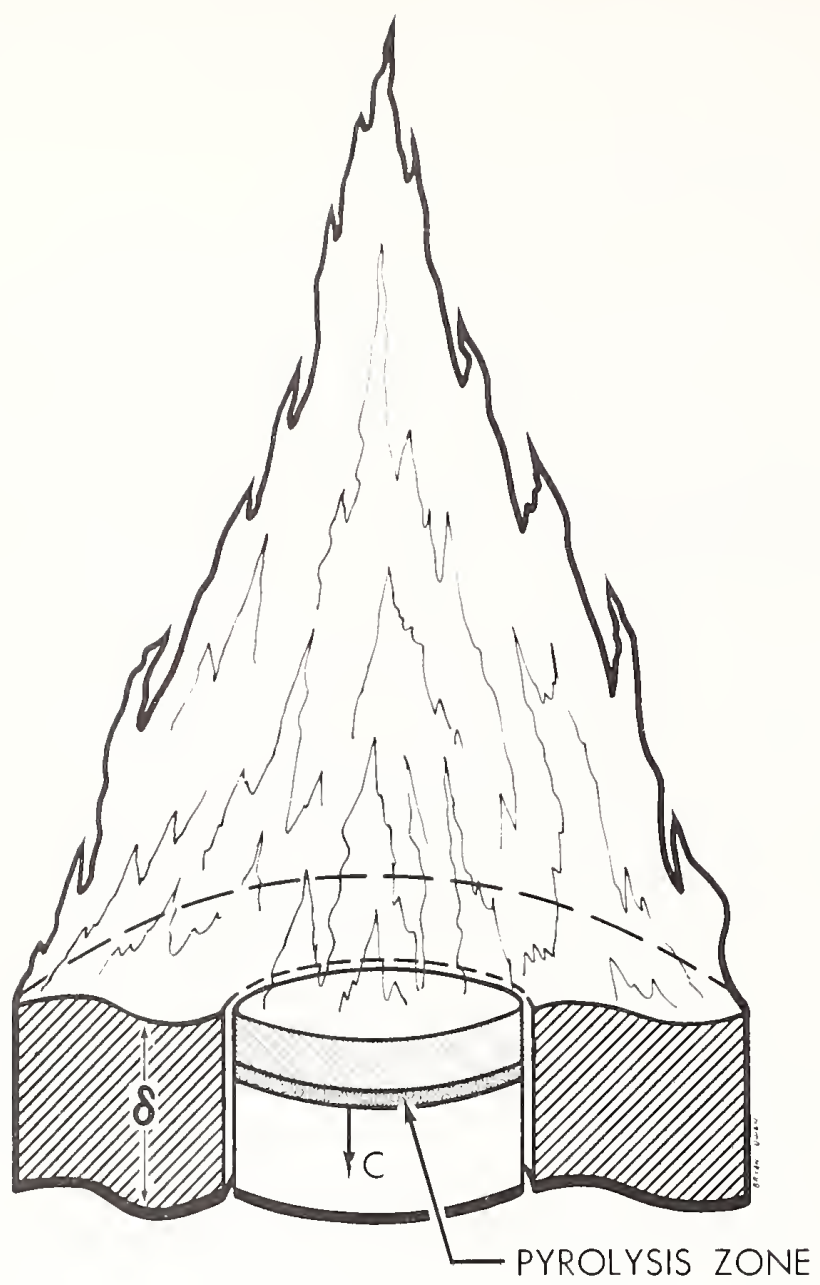

Figure 1.--A horizontal pyrolysis zone moving downward at a rate, $C$, through a weighed fuel basket of depth, $\delta$. A doughnut-shaped basket surrounds the weighed basket to eliminate edge effects.

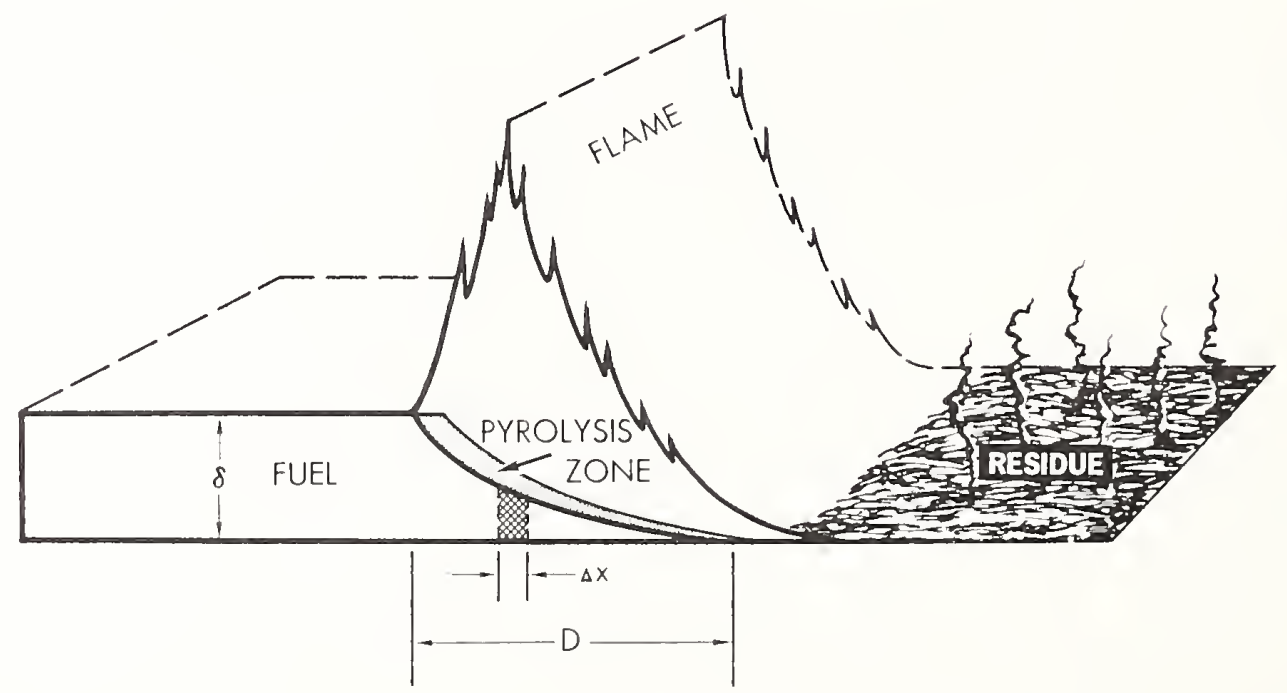

Figure 2.--A cross-sectional view of a fire spreading horizontally through a fine fuel (complete bumout). A weighed fuel slice is illustrated by $\Delta x$. The lower boundary of the pyrolysis zone is the ignition interface with the fuel. 


\section{FXPERIMENTAI PROCEDURE}

The experiment was conducted in the combustion chamber of the Northern Forest Fire Laboratory. The combustion chamber is connected to an environmental conditioning facility capable of maintaining humidity within \pm 1.5 percent and temperature within $\pm 33^{\circ} \mathrm{F}$ $\left( \pm 0.5^{\circ} \mathrm{C}\right)$. The entire series of experimental burns was run at $80^{\circ} \mathrm{F}\left(27^{\circ} \mathrm{C}\right)$ and 20 percent relative humidity, resulting in a 5 percent equilibrium moisture content for the fuel. The burns were conducted under an exhaust flue in the center of the combustion chamber 44 by 44 by $66 \mathrm{ft}(13.4$ by 13.4 by $20.1 \mathrm{~m}$.

A wire mesh basket (13 by $13 \mathrm{~mm}$ grid mesh size), $1 \mathrm{ft}^{2}\left(929 \mathrm{~cm}^{2}\right.$ ) in circular area and $0.5 \mathrm{ft}(15.2 \mathrm{~cm})$ deep was used to contain the fuel. Square cut aspen wood excelsior (Populus tremuloides Michx.), $0.07 \mathrm{~cm}$ in cross-sectional dimension (a fine fuel) was used; the same fuel was used in the original spreading fire experiment to which the burning basket results are to be compared. The particle density was $0.40 \mathrm{~g} / \mathrm{cm}^{3}$. Different packing ratios were obtained by changing the load while holding the depth fixed. A doughnut-shaped basket with an annular space of $0.5 \mathrm{ft}(15.2 \mathrm{~cm})$ and identical depth and packing ratio surrounded the inner basket (fig. 1) to eliminate edge effects and thus maintain a horizontal planar combustion front as the fire moves downward through the inner basket. Separation between the baskets is highly important. An annular space of one-fourth inch $(0.6 \mathrm{~cm})$ separating the inner and outer baskets was optimum for these tests. A larger space will result in increased burning within the open annular space deteriorating the horizontal combustion front, whereas a smaller space will result in serious disturbance to the load measurement through connecting bridges occasioned by heat warping the adjacent wire mesh walls of the baskets.

A string presoaked in xylene, a highly flammable fluid, was laid back and fourth over the upper surface of the fuel to insure uniform ignition. The load was monitored by a load cell transducer located below the inner fuel basket and insulated from the heat by baffles that also prevented airflow through the annular space between the center basket and the outer ring of fuel.

\section{RESULTS}

Figure 3 is a representative set of fuel load histories for each packing ratio, $\beta$. The load-loss rate was obtained simultaneously with the load history by electronically differentiating the signal from the load cell transducer. The differentiated signal was also used to determine the first indication of weight loss for the curves in figure 3 because of its greater sensitivity to changes in the load. Except for $\beta=0.065$, each curve has an initial negligible load loss. 


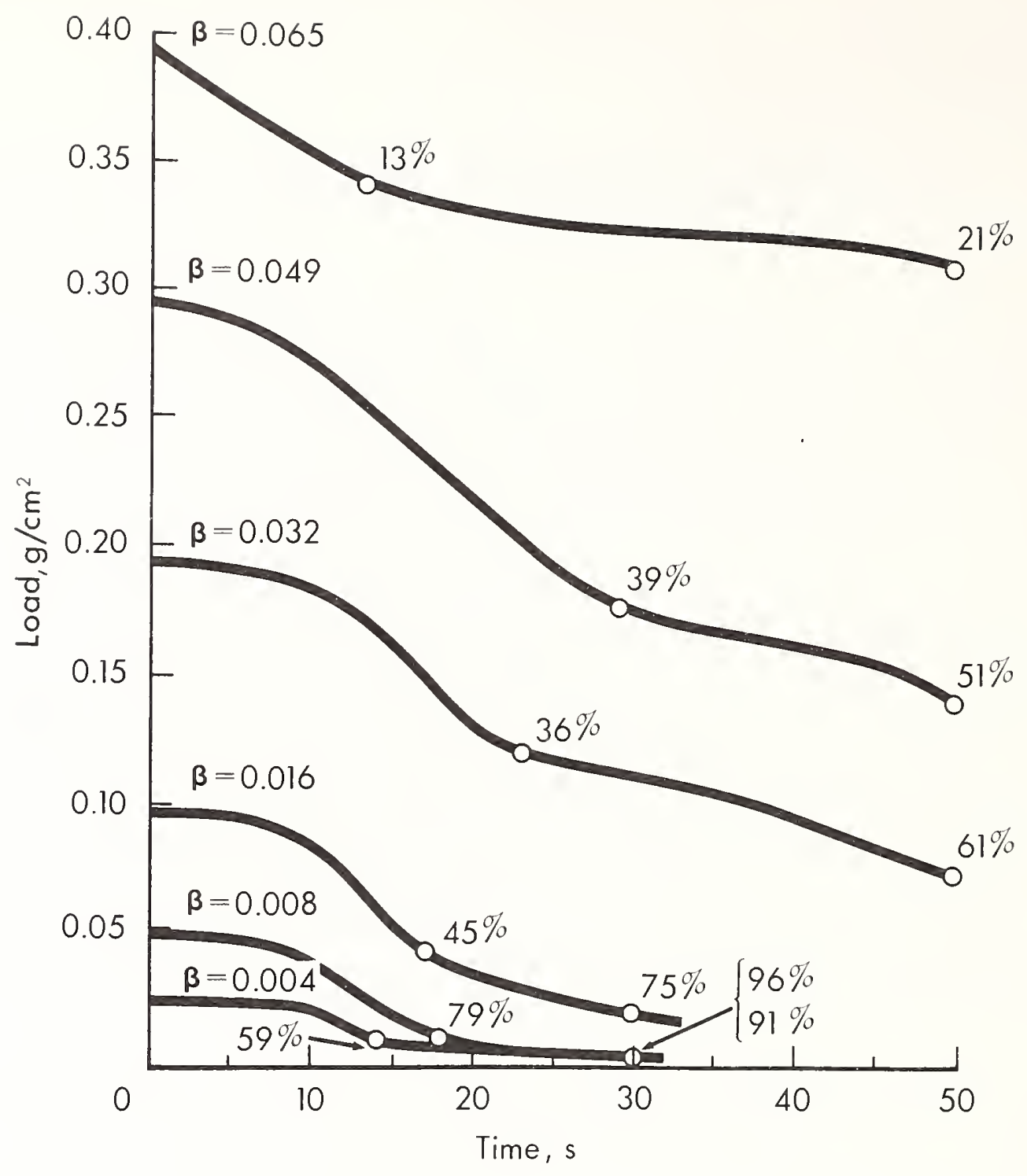

Figure 3.--Typical load histories of buming fuel baskets at six different packing ratios. The percent load loss through combustion is indicated at the end of the first major period of fuel consumption and at 30 seconds for $\beta=0.004$ to $\beta=0.016$ and at 50 seconds for $\beta=0.032$ to $\beta=0.065$.

Five replications of the load history were made at six packing ratios from 0.004 to 0.065 . Table 1 is a compilation of the maximum load-loss rate, $\dot{w}$, obtained from the burning basket. Table 2 contains Rothermel's original data for excelsior from horizontal spreading fires. Both sets of data are displayed in figure 4 along with a prediction of $\dot{w}$ according to Rothermel (1972) (appendix B). The prediction differs from the original excelsior data because the results of other fuel sizes were amalgamated by Rothermel to obtain the generalized expression for reaction velocity and thus the maximum load-loss rate. 
:

8

.

उँ

$\checkmark 8$

(4)

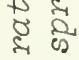

क ग

ON*

$1+70$

वै के

0 .

\&

5
5

है

i

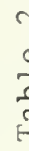

$4 \cdot \frac{8}{0}$

- 0 ०

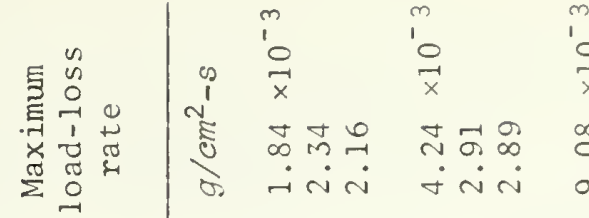

$i_{x}^{m}$

$m$

$i$

$\frac{1}{x}$

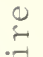

舟然要

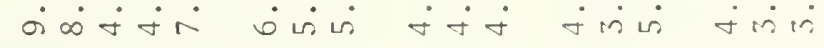

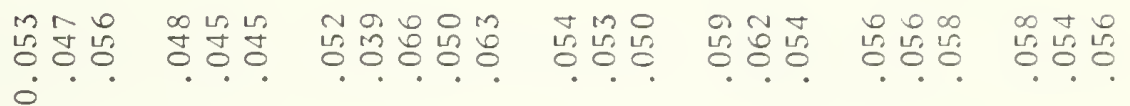

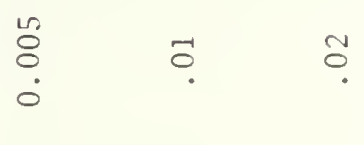

$\stackrel{2}{\circ}$

巳.

$\stackrel{2}{\circ}$

8

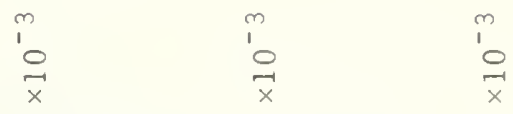

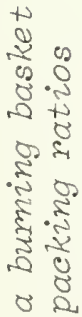

क्ष

is $\hat{q}_{1}$

\&

क त

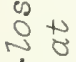

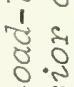

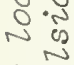

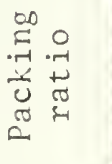

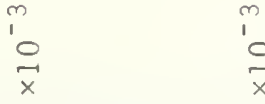

$\stackrel{0}{x}$

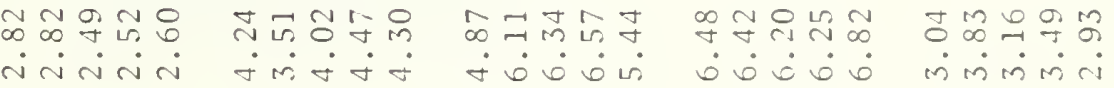

$\stackrel{2}{\circ}$

$\stackrel{2}{\circ}$

$\stackrel{2}{\circ}$

$\stackrel{2}{\circ}$

농

要娄 0

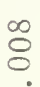

$\stackrel{0}{0}$

is

용 


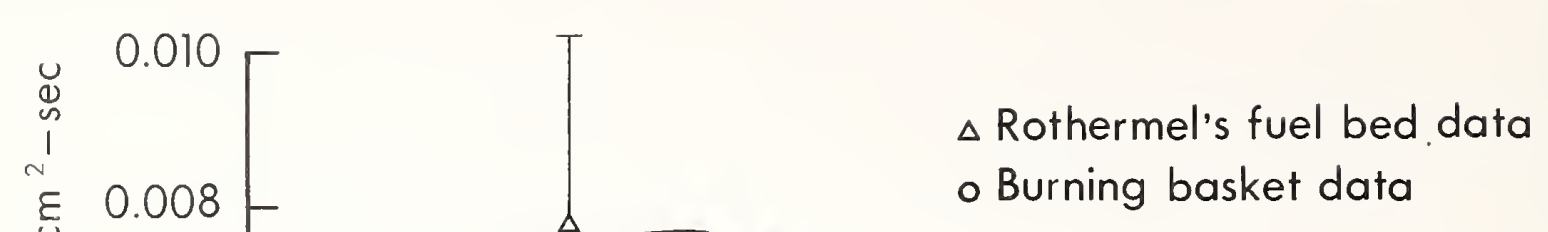

Figure 4.--A plot of the maximum load-loss rate, $\dot{w}$, versus the packing ratio, $B$, for excelsior bumed in a basket and in a fuel bed. The continuous curve was obtained from the expression for $\dot{w}$ in appendix $A$. The upper and lower extreme are the standard deviation from the mean.

\section{DISCUSSION}

The data contained in tables 1 and 2 for the two different methods of obtaining the maximum load-loss rate do not lend themselves to a simple comparison at the same packing ratios. However, assuming that a quadratic model fitṣ these data, we can approximate each data set with a quadratic regression curve, $\dot{w}$ regressed on $\beta$, and compare these curves to a quadratic regression of the composite of both data sets. The composite curve expresses fuel loss rate as accurately as the individual data sets if the composite curve has a sum of squared errors (SSE) (squared differences between observed and predicted from quadratic model) not significantly greater than the sum of SSE's from the separate curves. It then follows that the curves are not dissimilar. A statistical test of the data from tables 1 and 2 (appendix C) shows that it is very unlikely that the two data sets are different.

The early load history (fig. 3) of the burning fuel follows a declining sigmoid curve. Shape of the curve varies with packing ratio and is distinguished from other curves through the maximum load-loss rate occurring at the inflection. It is important to determine if the depth was sufficient to achieve the characteristic maximum load-loss rate for each packing ratio. Fuel consumption efficiency is a means of examining this 
question. It is indicated in figure 3 at the end of the curve and in the region of increasing slope (second knee except at $\beta=0.65$ ) following the inflection of the initial sigmoid curve. For $\beta=0.032$ to $\beta=0.065,39$ to 79 percent of the fuel still remains at 50 seconds--well after the initial sigmoid load history. Consequently, the depth, $15.2 \mathrm{~cm}$, was sufficient for $\beta=0.032$ to $\beta=0.065$. For $\beta=0.004$ to $\beta=0.016$, as little as 4 percent of the fuel remains at 30 seconds; however, each curve is sigmoid and shows at least 17 percent more fuel consumed beyond the second knee, indicating that the initial sigmoid curve was not foreshortened by lack of fuel depth.

In the spreading fire, the major rate of fuel consumption is near the front of the combustion zone--consistent with its early occurrence in the fuel basket--and is of prime importance to the propagation of the fire (Frandsen and Rothermel 1972).

Converting an idealized load history to load-loss history provides us with an easy reference for comparing the dynamics of burning fuel baskets of constant $\beta$ having different depths (initial loads). Because the fuel below the pyrolysis zone has no effect upon the present load-loss history, we can see that the load-loss curve for an extreme depth will have all the characteristics of load-loss curves of lesser depth (fig. 5), except that the period of constant load-loss rate becomes longer. The slope of the curves in figure 5 to the right of the second knee is dependent on char buildup. Char formation depends on the mineral content of the fuel and increases with oxygen depletion that in turn increases with time as the pyrolysis zone travels down into the basket. The char buildup for excelsior is negligible up to and including the maximum load-loss rate because the maximum rate occurs early in the load history and the mineral content is low $(0.03$ percent). Whatever the effect, it is the same for both the slice and the basket.

Figure 5.--An idealized roadloss history of a buming fuel basket of extreme depth, curve $D$, having simizar characteristics to a basket of lesser depth, curves $C$ down to $A$.

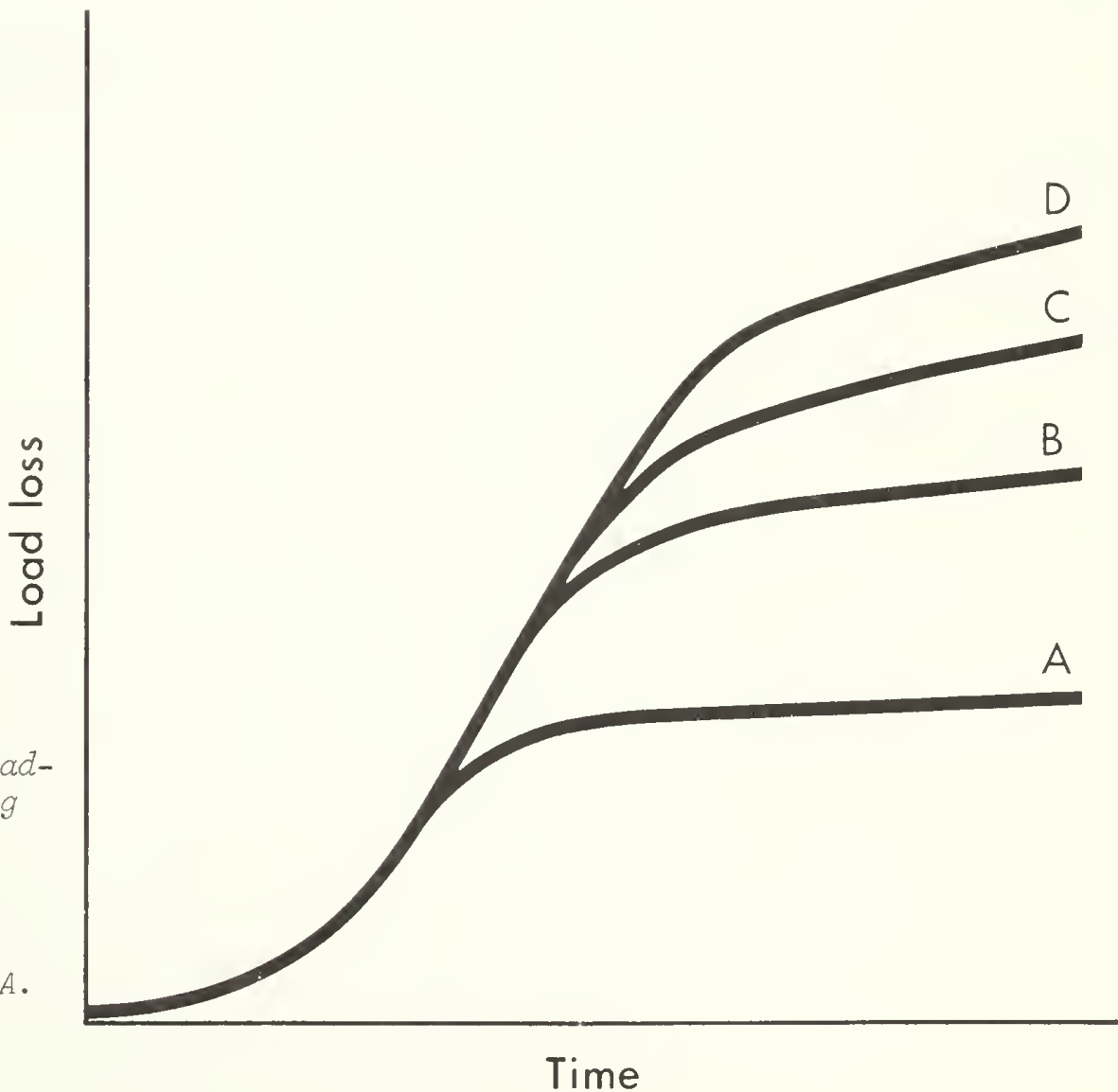


The statistical test in appendix $\mathrm{C}$ indicates that the alternative method presented here can be used for fuel near the size of excelsior to obtain the reaction velocity used by Rothermel to describe the dynamics of a horizontally spreading fire. "Investigations at larger fuel sizes are necessary to extend the range of the usefulness of this method.

This method should be useful in studying fire spread in forest fuels comparable in size to excelsior. Some specific applications that come to mind are; dependence of fire spread on natural variables such as mineral content, moisture content, extractive content, and packing ratio, and also the efficacy of fire-retarding chemicals.

\section{PUBLICATIONS CITHD}

Frandsen, W. H., and R. C. Rothermel.

1972. Measuring the energy-release rate of a spreading fire. Combust. and Flame $19: 17-24$.

Rotherme1, R. C.

1972. A mathematical model for predicting fire spread in wildland fue1s. USDA

For. Serv. Res. Pap. INT-115, 40 p. Intermt. For. and Range Exp. Stn., Ogden, Utah.

Draper, N. R., and H. Smith.

1966. Applied regression analysis. 407 p. John Wiley and Sons, Inc., New York. 
APPENDIX 


\section{Appendix A}

\section{Terms}

\begin{tabular}{|c|c|c|c|}
\hline SYMBOL & & DEEINITION & UNIT \\
\hline$\dot{w}$ & $=$ & Maximum load-loss rate & $\mathrm{g} / \mathrm{cm}^{2}-\mathrm{s}$ \\
\hline $\mathrm{n}$ & $=$ & Net original ovendry load (less inorganics) & $\mathrm{g} / \mathrm{cm}^{2}$ \\
\hline T & $=$ & Reaction velocity & $s^{-1}$ \\
\hline$\Gamma^{\prime}$ & $=$ & Optimum reaction velocity & $s^{-1}$ \\
\hline $\max$ & $=$ & Maximum optimum reaction velocity & $s^{-1}$ \\
\hline $\mathrm{h}$ & $=$ & Low heat content of fuel & $\mathrm{cal} / \mathrm{g}$ \\
\hline R & $=$ & Reaction intensity & $\mathrm{cal} / \mathrm{cm}^{2}-\mathrm{s}$ \\
\hline$\delta$ & $=$ & Fuel depth & $\mathrm{cm}$ \\
\hline & $=$ & Surface area-to-volume ratio & $\mathrm{cm}^{-1}$ \\
\hline & $=$ & $\begin{array}{l}\text { Packing ratio, the fraction of bulk volume } \\
\text { occupied by fuel }\end{array}$ & $\mathrm{cm}^{3} / \mathrm{cm}^{3}$ \\
\hline op & $=$ & Optimum packing ratio & $\mathrm{cm}^{3} / \mathrm{cm}^{3}$ \\
\hline & $=$ & Ovendry particle density & $\mathrm{g} / \mathrm{cm}^{3}$ \\
\hline & $=$ & Mineral damping coefficient & \\
\hline & $=$ & Moisture damping coefficient & \\
\hline 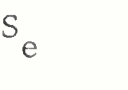 & $=$ & Silica free ash content & $\begin{array}{l}\text { Fraction } \\
\text { of ovendry }\end{array}$ \\
\hline $1_{f}$ & $=$ & Fuel moisture content & weight \\
\hline
\end{tabular}




\section{Appendix B}

\section{Derivation of Maximum Load-Loss Rate}

Beginning with $\dot{\mathrm{w}}=\mathrm{w}_{\mathrm{n}} \Gamma$, the net load is expressed as

$$
w_{n}=\rho_{p} \beta \delta
$$

where

$\rho_{p}=$ ovendry particle density

$\delta=$ depth of the fuel basket or fuel slice

$\beta=$ packing ratio, the fraction of the bulk volume occupied by fuel.

The other term in the expression for $\dot{w}$ is the reaction velocity, $\Gamma$. Rothermel (1972) provides a set of parametric equations for obtaining $\Gamma$ from initial fuel parameters.

where

$$
\Gamma=\eta_{\mathrm{s}} \eta_{\mathrm{m}} \Gamma^{-}
$$

$$
\begin{aligned}
& n_{s}=\text { mineral damping coefficient }=f(\text { silica free ash content) } \\
& n_{m}=\text { moisture damping coefficient }=f \text { (fuel moisture content) } \\
& \Gamma^{\prime}=\text { optimum reaction velocity }
\end{aligned}
$$

and

$$
\begin{aligned}
& \Gamma^{\prime}=\Gamma_{\max }^{\prime}\left(B / \beta_{o p}\right)^{A} \exp \left[A\left(1-\beta_{0} / \beta_{o p}\right)\right] \\
& \Gamma_{\max }^{\prime}=\sigma^{1.5}\left(495+0.0594 \sigma^{1.5}\right)^{-1} \\
& B_{\text {op }}=3.348 \sigma^{-0.8189} \\
& A^{A}=1 /\left(4.774 \sigma^{-1}-7.27\right) \\
& \sigma \quad=\text { particle surface area-to-volume ratio }
\end{aligned}
$$

Substituting $w_{n}$ and $\Gamma$ into $\dot{w}$ gives

$$
\dot{w}=\rho_{\mathrm{P}} \delta n_{\mathrm{s}} n_{\mathrm{m}} \beta \Gamma^{\prime}
$$

From Rothermel's (1972) original data

$$
\begin{aligned}
& \rho_{p}=26.12 \mathrm{lbs} / \mathrm{ft}^{2} \\
& \delta=0.375 \mathrm{ft} \\
& n_{m}=0.694 \quad \& \mathrm{M}_{\mathrm{f}}=0.05 \\
& n_{s}=0.507 \quad \& \mathrm{~s}_{\mathrm{e}}=0.0036
\end{aligned}
$$

Substituting into $\dot{w}$ we have

$$
\dot{\mathrm{w}}=0.0280 \mathrm{~B}^{\prime}
$$

with $\sigma=1,848 \mathrm{ft}^{-1}$ for excelsior

$$
\Gamma^{\prime}=15.237 \mathrm{e}^{0.3498}\left[\beta^{\prime} \mathrm{e}^{-\beta^{\prime}}\right]^{0.3498}
$$

where

$$
\beta^{\prime}=\beta / 0.00707
$$




\section{Appendix C \\ Statistical Test}

Statistical test of the similarity between the maximum load-loss rate dependence on packing ratio of the alternative burning basket method and the horizontally spreading fire.

The SSE and degrees of freedom, d.f., are given in the following tabulation. The model assumes a second degree polynomial.

\begin{tabular}{|c|c|c|}
\hline Data set & $\mathrm{SSE}^{*}$ & $\mathrm{~d} . \mathrm{f} .=\mathrm{n}-3$ \\
\hline Verticle burn, $\operatorname{SSE}(V)$ & $9.5600 \times 10^{-6}$ & 27 \\
\hline Horizontal burn, SSE $(H)$ & $43.6092 \times 10^{-6}$ & 20 \\
\hline Composite, SSE (C) & $58.0511 \times 10^{-6}$ & 50 \\
\hline
\end{tabular}

Forming $F$ value according to Draper and Smith (1966)

$$
F=\frac{(\Delta S S E / \Delta d \cdot f \cdot)}{(\operatorname{SSE}(V+H) / d \cdot f \cdot(V+H))}
$$

Therefore

$$
\begin{aligned}
& F=\frac{\left(4.8819 \times 10^{-6 / 3}\right)}{\left(53.1692 \times 10^{-6 / 47)}\right.}=\frac{(4.8819)(47)}{(53.1692)(3)} \\
& F=1.4385
\end{aligned}
$$

Given no difference in the two sets of data the probability of such a value for $F$, is 0.24 . Therefore, we accept the hypothesis that both methods are estimating the same result. 
Frandsen, William H., and Robert D. Schuette.

1978. Fuel burning rates of downward vs. horizontally spreading fires. USDA For. Serv. Res. Pap. INT-214, 12 p. Intermt. For. and Range Exp. Stn., Ogden, Utah 84401.

Describes a vertical, cylindrical fuel array that requires less fuel and less time to set up and to measure combustion rates than the flat fuel arrays used previously in laboratory studies of fire. Rates of combustion were comparable in horizontally and vertically (downward) spreading experimental fires.

KEYWORDS: fire spread, excelsior fuel, burning rate, load-loss rate, fire behavior.

Frandsen, William H., and Robert D. Schuette.

1978. Fuel burning rates of downward vs. horizontally spreading fires. USDA For. Serv. Res. Pap. INT-214, 12 p. Intermt. For. and Range Exp. Stn., Ogden, Utah 84401.

Describes a vertical, cylindrical fuel array that requires less fuel and less time to set up and to measurc combustion rates than the flat fuel arrays used previously in laboratory studies of fire. Rates of combustion were comparable in horizontally and vertically (downward) spreading experimental fires.

KEYWORDS: fire spread, excelsior fuel, burning rate, load-loss rate, fire behavior. 
Headquarters for the Intermountain Forest and Range Experiment Station are in Ogden, Utah. Field programs and research work units are maintained in:

Billings, Montana

Boise, Idaho

Bozeman, Montana (in cooperation with Montana State University)

Logan, Utah (in cooperation with Utah State University)

Missoula, Montana (in cooperation with University of Montana)

Moscow, Idaho (in cooperation with the University of Idaho)

Provo, Utah (in cooperation with Brigham Young University)

Reno, Nevada (in cooperation with the University of Nevada)
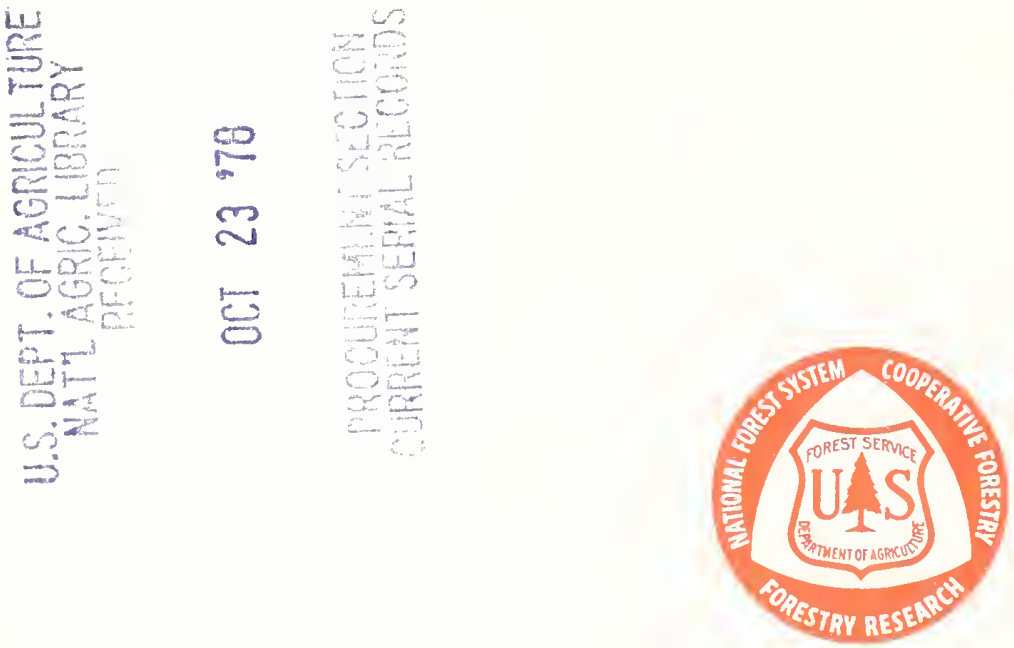